\section{COMPREENSÕES SOBRE A TEMÁTICA AMBIENTAL E A FORMAÇÃO INICIAL DE PROFESSORES DE CIÊNCIAS E BIOLOGIA.}

Victor Hugo de Oliveira Henrique

Luciano Fernandes Silva

\section{Resumo}

Este trabalho analisou as compreensões que licenciandos em Ciências Biológicas de uma universidade pública possuem sobre a temática ambiental. Foi realizada uma pesquisa de caráter qualitativo e os dados foram coletados por meio de, questionários e entrevistas semiestruturadas. A análise baseou-se na análise de conteúdo e foram identificadas 4 categorias. As análises direcionam que as compreensões sobre a temática ambiental apresentada pelos futuros professores, a concepção ecológica foi a que mais apresentou unidades de registro, seguida pela concepção crítica, utilitarista e por fim a naturalista. É percebido ainda pelos licenciandos uma concepção baseada em princípios biológicos acera da temática ambiental. Esperamos que com os conhecimentos construídos por meio dessa pesquisa possa contribuir na discussão sobre a formação inicial de professores de biologia e trazer reflexões sobre a educação ambiental concebida nas escolas por meio dos professores de biologia.

Palavras-chave: Temática ambiental. Ensino de biologia. Futuros professores.

\section{UNDERSTANDINGS \\ ON \\ ENVIRONMENTAL ISSUES AND THE \\ INITIAL FORMATION OF SCIENCE AND BIOLOGY TEACHERS}

Keywords: Environmental theme. Teaching biology. Future teachers. 


\section{CONOCIMIENTOS SOBRE TEMAS AMBIENTALES Y LA FORMACIÓN INICIAL DE PROFESORES DE CIENCIAS Y BIOLOGÍA}

\section{Resumen:}

Este artículo analizó los entendimientos que los estudiantes universitarios de Ciencias Biológicas de una universidad pública tienen sobre el tema ambiental. Se realizó una investigación cualitativa y se recopilaron datos a través de cuestionarios y entrevistas semiestructuradas. El análisis se basó en el análisis de contenido y se identificaron 4 categorías. Los análisis señalan que la comprensión sobre el tema ambiental presentada por los futuros maestros, la concepción ecológica fue la que presentó más unidades de registro, seguida por la concepción crítica, utilitaria y finalmente la naturalista. Los estudiantes universitarios también perciben una concepción basada en principios biológicos sobre el tema ambiental. Esperamos que con el conocimiento construido a través de esta investigación pueda contribuir a la discusión sobre la formación inicial de maestros de biología y traer reflexiones sobre la educación ambiental concebida en las escuelas a través de maestros de biología.

Palabras clave: Tema ambiental. Enseñanza de biología. Futuros docentes

\section{Introdução}

A história nos mostra que o ser humano, durante séculos, se imaginou no centro do universo e, tendo a natureza ao seu serviço, "apropriou-se de seus processos, alterou seus ciclos, redefiniu seus espaços [...]" (BRASIL, 1998a, p.22).

Diante disso, o processo educativo passou a ser pensado de uma maneira que possibilite minimizar o quadro de desequilíbrios instalados, pois, ainda que não consiga mudar os rumos do planeta, a educação é condição necessária para isso (BRASIL, 1998b).

Sendo assim, a compreensão que o professor possui sobre o conhecimento reflete diretamente em sua prática pedagógica. Diante deste cenário, temos considerado relevante elaborar estudos que se voltam para a compreensão da temática ambiental por futuros professores. Para Trivelato (2001), a inserção da temática ambiental no currículo escolar não foi resultado de um processo de integração de diferentes disciplinas, mas de responsabilização de algumas, sendo que Ciências da Natureza e Biologia foram apontadas como caminhos preferências para levar a EA para a escola.

Um dos desafios para implementação dessa abordagem, volta-se para a formação de professores de Ciências Biológicas. Nesta perspectiva, consideramos que para que a Educação Ambiental (EA) se desenvolva efetivamente no âmbito escolar, os professores precisam ultrapassar a tendência tradicional de atribuir à EA exclusivamente conteúdo das Ciências Biológicas, como a ecologia.

Nesse sentido, é importante ressaltar que "[...] ao confinar a EA quase exclusivamente ao ensino de Biologia, acaba por reduzir a abordagem necessariamente complexa, multifacetada, ética e política das questões ambientais aos seus aspectos biológicos" (GRÜN, 1996, p. 105). Os professores de Biologia têm papel preponderante na educação para o ambiente, mas Guimarães (2010, p.106) reforça [...] é importante que a biologia ande de mãos dadas com as novas ciências da complexidade que nos ensinam a procurar padrões globais em vez de especificidades reducionistas [...]". O professor de Biologia deveria se aproximar das outras áreas do conhecimento, no sentido de colocar a 
temática ambiental em evidência permanente, tendo sempre a intenção didática de manter o caráter interdisciplinar do saber ambiental.

É importante ressaltar que a maneira como a EA foi sendo ao longo dos últimos quarenta anos implementada no ensino formal pode exercer influência no discurso e na prática do professor relativos à temática ambiental. Esse processo de implementação resulta de uma história social, política, econômica e cultural que antecede nossa atual compreensão da abordagem da Temática Ambiental no ensino. Dessa maneira, nossa compreensão atual é influenciada por uma historicidade, que determina também nossa práxis. No entanto, é importante salientar que as características do trabalho docente em relação à Temática Ambiental também sofrem influência de outros fatores que permeiam a trajetória de vida pessoal e profissional do professor.

A partir das diferentes iniciativas direcionadas para a discussão das compreensões da temática ambiental e do processo educativo construídos por professores (ou futuros professores), alguns pesquisadores têm atuado em torno dessa temática por meio de pesquisas. Destacamos o trabalho de Benetti (2004) que procurou estudar a perspectiva relacionada a temática ambiental apresentada por professores em formação inicial de um curso de Licenciatura em Ciências Naturais e Biologia, que frequentavam a disciplina Prática de Ensino. Os dados da pesquisa revelam que a relação entre os conteúdos da Biologia ou das Ciências Naturais com as questões ambientais não ocorrem de maneira espontânea numa perspectiva de transversalidade, ou ainda, tendo como eixo um enfoque ecológico. Destacamos também o trabalho de Silva (2007) que se voltou para os licenciandos em Física de um curso de licenciatura de uma universidade pública do estado de São Paulo, e que a partir dos dados da pesquisa, podemos concluir que não há, por parte dos licenciandos, uma compreensão mais ampla do significado da temática ambiental.

Tendo em vista que as compreensões acerca da Temática Ambiental do futuro professor de Biologia podem vir a ser um obstáculo para a realização de trabalhos com aspectos da crise ambiental, delineamos uma pesquisa com o objetivo de identificar e analisar que aspectos da temática ambiental são destacados pelos licenciandos do último ano de um curso de licenciatura em ciências biológicas de uma universidade pública brasileira.

\section{Procedimentos Metodológicos}

Esta pesquisa consiste em um trabalho de natureza qualitativa. Segundo Chizzotti (2003) a pesquisa qualitativa recobre um campo transdisciplinar que envolve as ciências humanas e sociais, assumindo diversas formas de análise e busca encontrar os sentidos dos fenômenos humanos e entender seus significados.

A coleta de dados teve início após a aprovação do projeto pelo Comitê de Ética em Pesquisa em Seres Humanos (Parecer número 1.426.274) e aconteceu por meio de entrevistas semiestruturadas e a aplicação questionários. Optamos pela "triangulação de dados" devido à utilização de diferentes fontes de evidências, aumentando assim, o rigor e a profundidade da investigação. Entendemos que a triangulação se caracteriza como um ponto na coleta de dados significativo, possibilitando a dedicação do pesquisador ao "problema em potencial da validade do constructo, uma vez que várias fontes de evidências fornecem essencialmente várias avaliações do mesmo fenômeno" (YIN, 2010, p.128).

A interpretação dos dados foi realizada por meio da metodologia de análise de conteúdo do tipo categorial temática, que tem como uma das referências o trabalho de Bardin (2011). Para a realização da análise de conteúdo dessa pesquisa, procedemos às seguintes etapas: 1) Pré-análise: que de acordo com Bardin (2011) é a etapa de organização do material, transcrição das entrevistas, leituras flutuantes e escolha do material. 2) Exploração do material: é o momento da codificação - no qual iniciamos a sistematização do material obtido a partir de unidades de significados, que se constituíram em unidades de registro, as quais permitem uma descrição das características pertinentes do conteúdo. 3) Categorização: etapa em que as unidades de registros foram organizadas em categorias e subcategorias a partir da interpretação dos dados. 4) Tratamento dos resultados: apresentamos os dados das categorias por meio de um texto de maneira que expressasse o conjunto 
de significado nas diversas unidades de registro. 5) Análise: momento que foi realizado a análise das categorias e subcategorias objetivando a compreensão profunda do conteúdo estudado.

Os sujeitos de pesquisa consistiram em um grupo formado por 20 alunos de um curso de Licenciatura em Ciências Biológicas de uma universidade pública localizada no estado de Mato Grosso, região centro-oeste do Brasil.

\section{Considerações sobre a temática ambiental apresentada pelos licenciandos}

Apresentaremos agora considerações sobre a visão dos licenciandos referente à temática ambiental. Utilizamos uma categoria a priori, proposta por Moares (2005), e três outras categorias que emergiram após a leitura dos dados obtidos a partir de uma entrevista e de um questionário apresentado aos licenciandos realizada ao longo do semestre letivo. As categorias e as unidades de registro são apresentadas no Quadro 1.

Quadro 1 - Considerações dos licenciandos sobre a temática ambiental

\begin{tabular}{|c|c|c|}
\hline Categorias & Unidades de registro & $\begin{array}{c}\text { Frequência das } \\
\text { unidades de regis- } \\
\text { tros no questioná- } \\
\text { rio e na entrevista }\end{array}$ \\
\hline Naturalista & $\begin{array}{c}\text { Ser humano, homem, } \\
\text { poluição humana, con- } \\
\text { dição humana, culpa da } \\
\text { humanidade. }\end{array}$ & 4 \\
\hline Crítica & $\begin{array}{c}\text { Causas e consequências } \\
\text { da poluição, agrone- } \\
\text { gócio, consumismo, } \\
\text { agrotóxicos, organismos } \\
\text { geneticamente modifica- } \\
\text { dos, capital, globalização, } \\
\text { respeito a diversidade. }\end{array}$ & \\
\hline Ecológica & $\begin{array}{c}\text { Conteúdos ecológicos, } \\
\text { biologia da conservação, } \\
\text { ecologia, zoologia, botâ- } \\
\text { nica, saúde ambiental }\end{array}$ & \\
\hline Utilitarista & $\begin{array}{c}\text { Gerações futuras, falta } \\
\text { de recurso, sobrevivência } \\
\text { da humanidade, explora- } \\
\text { ção dos recursos naturais }\end{array}$ & 15 \\
\hline
\end{tabular}

A perspectiva naturalista foi elaborada a partir dos estudos de Moraes (2005). O autor, ao analisar as concepções de pesquisadores da área de ciências sociais sobre a temática ambiental, identificou três posturas que os pesquisadores assumem em relação a temática ambiental, a postura relacionada ao naturalismo, ao tecnicismo e ao romantismo.
Para o autor, na perspectiva naturalista, o ser humano é apontado como fator de alteração do equilíbrio do meio, sendo a relação ser humanonatureza percebida a partir das relações naturais, sem a mediação das relações sociais.

A transcrição e leitura das entrevistas indicaramnos que há núcleos de significados que nos remetem diretamente para as considerações de Moraes (2005) sobre uma perspectiva mais naturalista de compreensão sobre a temática ambiental. Quando - por exemplo nas entrevistas - perguntamos aos licenciandos, após suas atividades de regência nas escolas, sobre quais aspectos da temática ambiental abordaram na regência e/ou abordariam eu suas futuras aulas na escola recebemos respostas como a transcrita a seguir:

Eu entendo que temática ambiental é a relação ser humano e natureza, e não abordei por exemplo poluição que podem causar mutações e selecionando diversas espécies dentro daquele ambiente poluído, e é uma atividade causada pelo ser humano (Mario grifo nosso).

Então, eu falava muito sobre o impacto do homem no meio ambiente [...] Acredito que temos que conservar a natureza não pensando somente em nós, seres humanos, mas que ela é importante para uma gama de seres vivos também, mas usar o ser humano pode também sensibilizar os jovens. (Francisca grifo nosso)

Outros dados apontam para a mesma perspectiva como, por exemplo, aqueles obtidos com questionários, aplicados alguns dias antes dos licenciandos irem para as escolas exercer a atividade de regência. Para exemplificar apresentamos a seguir excertos retirados das respostas dos licenciados ao seguinte questionamentos "quais os principais problemas enfrentados pela sociedade atualmente?"

Por conta de questionamentos como esses, eu creio que os problemas ambientais são a verdadeira condição humana. (Mario - grifo nosso).

Ou ainda,

Os problemas ambientais que temos enfrentado, atualmente, são por nossa culpa. É problema nosso tentar solucionar. (Felícia - grifo nosso).

A leitura das informações coletadas nos 
possibilitou construir a categoria crítica. Nesta categoria identificamos como perspectiva crítica aqueles discursos que se aproximavam, mesmo que minimamente, de assuntos como o questionamento do modelo atual de economia, o consumismo exagerado, aspectos que relacionam a temática ambiental com a sociedade, a cultura e a política. Nesse sentido, Borheim (1985) diz que nesse tipo de discurso a maneira como o ser humano pensa e torna presente a natureza está articulado com a origem dos problemas ambientais.

O excerto a seguir, extraído de uma das entrevistas realizada após a atividade de regência, sobre quais aspectos da temática ambiental abordaram ou abordariam eu suas futuras aulas na escola, ajudanos a compreender melhor essa perspectiva:

\begin{abstract}
Poderíamos ter trabalhado a questão da poluição e seus efeitos nas células e assim gerar debates sobre o tema, falando das causas e dos efeitos da poluição causada principalmente pela grande produção industrial, claro, falar da poluição individual também, porque nossas aulas foram sobre origem da vida, célula e reino monera. (Mauricio - grifo nosso).
\end{abstract}

Nesse caso, podemos visualizar a preocupação com a modelo de produção industrial e seus efeitos no ambiente, como a poluição, que pode ter efeito direto nos organismos vivos, aproximando da perspectiva crítica.

Em outro excerto utilizado para identificarmos uma perspectiva crítica em relação a alguns aspectos da temática ambiental, o licenciando apresenta considerações sobre o uso intenso de agrotóxico, que é um assunto que gera diversos debates sobre o agronegócio e o meio ambiente, sobretudo na região centro oeste do Brasil.

Ao falar da célula animal e vegetal, eu falei sobre mutações, e dentre uma das causas de mutações é a poluição, principalmente por agrotóxicos, lembrei de uma palestra que assisti sobre o tema agrotóxico, e gerou discussão na sala, pois eu fazia perguntas como: Por que usar tanto agrotóxico? Para onde vai toda a soja ou o algodão produzido aqui no estado? etc. (Fabiana - grifo nosso)

Alguns assuntos indiretamente ligados a discussão de aspectos da temática ambiental, mas que geram debates polêmicos, foram abordados a partir de considerações mais simples, talvez pela diversidade de opiniões sobre a atual situação política do país, como o processo de impedimento do mandato da Presidenta Dilma Rousseff, em 2016. Importante destacar que este processo de impedimento foi articulado pela associação entre uma parcela significativa da sociedade, grandes grupos de mídia e parte do congresso brasileiro. Este assunto e outros ligados às políticas ambientais associadas ao governo da presidente deposta, parece gerar um certo desconforto nos licenciandos, sobretudo diante da possibilidade de discuti-los em sala de aula. Todavia, outros licenciandos conseguiram introduzir certos assuntos, como o modelo de produção, que se caracteriza na subcategoria crítica, como é exposto no excerto a seguir extraído de uma entrevista:

Falei sobre energia solar, energia eólica, energia por biomassa e falei dos impactos das grandes usinas hidrelétricas. Falei sobre como elas priorizam o lucro. Alguns alunos questionaram falando que precisamos pensar antes de falar sobre isso, pois ninguém quer abrir mão da energia elétrica, aí falei sobre o consumo de energia, que a maior parte vai para as indústrias e não para o consumo nas residências, ai já falei da grande produção industrial, que é para atender nossas luxurias e não nossas reais necessidades [...] mas não citei por exemplo a palavra "capitalismo", sei que essa produção em massa é oriunda do nosso sistema econômico, que é o capitalismo, mas não me senti com propriedades para falar assim tão diretamente, pois ai surgiriam assuntos que estão na mídia sobre comunismo, socialismo, Cuba, PT, etc, e não que eu não ache importante, eu acho, mas é que não tinha e ainda não tenho, preciso estudar mais, propriedades sobre o assunto. [Fani].

Os dados ainda indicam que 18 dos 20 licenciandos apresentaram considerações sobre a temática ambiental que se apoiam em conhecimentos do campo da Ecologia. Considerações desta natureza estão presentes em algumas manifestações que os estudantes fizeram ao longo das entrevistas, aplicadas após a atividade de regência nas escolas, quando questionamos sobre os aspectos da temática ambiental abordados ou que abordariam em suas aulas.

Os alunos foram levados para a área externa da escola e puderam observar os focos de decomposição, discutimos sobre a importância dos seres decompositores 
para a natureza e como eles estão ligados à cadeia alimentar. Foram observados vários materiais inorgânicos no terreno da escola e aproveitamos para conversar sobre a preservação ambiental. (Muriel - grifo nosso).

Ou ainda,

Comecei com introdução a biologia, áreas da biologia, método científico, origem dos seres vivos, com a geração da biogênese e biogênese, falei sobre Pasteur, sobre os coacervados de Oparin, sobre o experimento de Miller, hipótese autotrófica e heterotrófica e por fim sobre equilíbrio da natureza, ai nessa parte falei sobre um pouco da questão ambiental, de como o desmatamento pode quebrar o equilíbrio natural. (Fabiele - grifo nosso)

É possível visualizar a ênfase em conteúdos relacionados a conservação, preservação e equilíbrio ambiental, reforçando a perspectiva ecológica da Temática Ambiental e desarticulando com aspectos políticos, sociais, econômicos, culturais e no distanciamento do ser humano com a natureza.

Eu fiquei com aulas de relações ecológicas e introdução a ecologia, lembro que falei bastante das relações dos animais, e como é importante entendermos elas para convivermos em harmonia, mas não consigo de lembrar de relacionar o ser humano como parte da natureza. (Mouro).

É comum em cursos de ciências biológicas disciplinas relacionadas ao meio ambiente em uma perspectiva puramente ecológicas, para Araujo e França (2013) atrelar os conteúdos de EA apenas a disciplinas "ecológicas" acaba por majoritariamente ocorrer sob um viés conservacionista, "o que pode representar empecilhos e equívocos ao se trabalhar com a EA" (ARAUJO \& FRANÇA, 2013).

Existe uma proposta de inserção da temática ambiental nos cursos de formação de professores que envolve a adoção de uma nova racionalidade com mudanças estruturais nos currículos dos cursos de formação de professores a partir de uma "ressignificação tanto de conteúdos e metodologias quanto de estruturas educativas, num processo abrangente de integração da dimensão socioambiental", que é a ambientalização curricular (KITZMANN \& ASMUS, 2012).
A proposta de ambientalização curricular nos cursos de ciências biológicas pode parecer redundante já que em sua essência essa área do conhecimento envolve as questões ambientais. Porém em muitos cursos, pela influência do modelo positivista e cartesiano de ciência os conteúdos a serem ensinados nas disciplinas são extremamente fragmentados perdendo o pando de fundo ambiental que deveria permear todas as disciplinas desse curso, além do fato, do processo de ambientalização envolver também as questões sociais, políticas e culturais no currículo.

Os dados também indicam que 14 futuros professores possuem uma perspectiva que se aproxima de uma ideia de relação ser humano e natureza mais próximo da utilitarista. Essa perspectiva está relacionada com o valor que atribuímos a natureza. A natureza é vista como objeto a ser dominado, sendo ela considerada basicamente pelo seu valor de uso, perspectiva utilitarista, segundo a qual, as coisas possuem valor se puderem ser úteis para o ser humano (GRUN, 2007). Tal perspectiva pode ser visualizada nos enxertos extraídos dos questionários aplicado aos futuros professores antes da atividade de regência, quando questionados sobre os problemas ambientais.

Problemas ambientais em geral, são fatores que desencadeiam inúmeros efeitos negativos para a sociedade. Dentre esses efeitos estão à falta de recurso para sobrevivência da população e também o crescimento e surgimento de doenças em grande escala. (Marcelo - grifo nosso).

Pois precisamos dos recursos encontrados na natureza para nossa sobrevivência. Problemas que envolvem o meio ambiente, interferem diretamente na permanência da vida, por isso a importância de conhecer, preservar e conservar o meio no qual vivemos. (Fabia - grifo nosso).

Ou ainda.

A população humana está em crescimento constante e com ela as necessidades básicas também. Sendo a nossa maior fonte a natureza e seus recursos oferecidos que são limitados e mal utilizados. (Mouro).

Outro questionamento que surge nessa perspectiva é a conservação da natureza pensando nas gerações humanas futuras, ainda trazendo a 
perspectiva utilitarista da temática ambiental, ou seja, pensando no bem-estar unicamente dos seres humanos, esquecendo que as gerações futuras das outras formas de vida também precisam da natureza para sua sobrevivência.

É de extrema importância a sociedade discutir sobre o problema ambientais, refere-

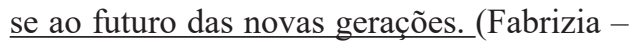
grifo nosso).

Tal posicionamento se aproxima da ética antropocêntrica, que segundo Felipe (2009), se caracteriza como o bem do ser humano, colocado no centro e acima do bem de qualquer outro organismo vivo, o atual momento de destruição de vidas não humanas é resultante desse modelo de ética. Em contraponto a ética antropocêntrica, temos a ética biociênctrica, que de acordo com Felipe (2009) desvia o eixo de interesse para o ser enquanto indivíduo sujeito de uma vida. Ou seja, não admite que a solução de qualquer conflito moral tenha somente em conta os interesses humanos; considera todos os seres vivos como sujeitos de direito, com valor intrínseco, independente da utilidade que esse ser tenha para o ser humano. No modo como a educação ambiental e o ensino de biologia são trabalhados na escola, percebe-se muito pouco do modelo de ética biocêntrica e cada vez mais uma intrumentalização dos indivíduos ao sistema social em que estão inseridos. Brugger (2004), alerta para o "adestramento ambiental" que ocorre nas escolas, pois este exclui a dimensão moral, reduzindo a educação a aspectos meramente técnicos, que pouco ou quase nada contribuem para uma formação realmente crítica, quanto às formas de relação dos seres humanos com o seu ambiente. Para Brugger, (2004): "infelizmente, é preciso admitir que adestramento em vez de educação é o que ocorre em diferentes níveis e áreas do ensino formal no nosso país".

\section{Considerações finais}

Este trabalho teve como objetivo identificar compreensões sobre a temática ambiental apresentada licenciandos em Biologia de uma universidade pública localizada no estado de Mato Grosso. O agrupamento com maior frequência de unidades de registro foi a concepção ecológica da temática ambiental, seguida pela concepção crítica, que se aproxima, mesmo que minimamente de aspectos econômicos, sociais e/ ou culturais, depois a concepção utilitarista e por fim o agrupamento da concepção naturalista.

Percebemos no trabalho que os futuros professores se identificam com a ideia da importância de realizar trabalhos educativos com aspectos da temática ambiental, porém, a maioria dos estudantes pesquisados não consideram que esta temática tenha uma perspectiva além da biológica. O ambiente é cada vez mais um fenômeno sociocultural (TOZZONI-REIS, 2001) e estudar o ambiente, ou educar ambientalmente, é cada vez mais tomar decisões que envolvem a relação ambiente-sociedade.

As possibilidades de inserção da temática na formação inicial dos professores são variadas e as opções por uma ou várias dessas alternativas devem sempre objetivar uma formação coerente com a realidade apresentada. É importante levar em conta que o que se pretende é uma formação que seja capaz de levar os discentes a desenvolver a competência para contextualizar os conhecimentos, integrando-os em seu conjunto (MARTINAZZO, 2002).

Essa formação inicial é essencial para que a discussão acerca da crise ambiental, possa começar na educação básica, com a intervenção do professor, que reformula o conteúdo de suas matérias, tomando como objetivo os problemas socioambientais do mundo atual (LEFF, 2001), porém, para que isso aconteça, o investimento em uma formação de qualidade é imprescindível.

A partir dos resultados obtidos, suscitou-se outras questões que abrem possibilidades para novas pesquisas na área, as quais poderiam investigar, por exemplo, a formação do futuro professor de biologia a partir do currículo do curso a partir do Projeto Político do Curso, levando em consideração, ou não, aspectos locais relacionados a temática ambiental.

\section{Referências}

ARAUJO, M. L. F., \& FRANÇA, T. L. Concepções de Educação Ambiental de professores de biologia em formação nas universidades públicas federais do Recife. Educar em Revista, v. 50, p. 237-252, 2013. 
BARDIN, L. Análise de conteúdo. São Paulo: Edições 70, 2011.

BENETTI, B. O Tácito e o Explícito: a formação de professores de Ciências Naturais e Biologia e a Temática Ambiental. 2004. 213f. Tese de doutorado (Doutorado em Educação escolar) - Universidade do Estado de São Paulo, Araraquara, 2004.

BORNHEIM, G. Filosofia e Política ecológica. Revista Filosófica Brasileira. 2(1): 16 - 24, 1985.

BRASIL.SecretariadeEducaçãoFundamental. Parâmetros Curriculares Nacionais: Ciências Naturais. Brasília: MEC/SEF, 1998a.

BRASIL.SecretariadeEducaçãoFundamental. Parâmetros Curriculares Nacionais: $3^{\circ}$ e $4^{\circ}$ ciclos: apresentação dos temas transversais. Brasília: MEC/SEF, 1998b.

BRUGGER, P. Educação ou adestramento ambiental? 3. ed. Florianópolis-SC: Letras Contemporâneas, 2004.

CHIZZOTTI, A. A pesquisa qualitativa em ciências humanas e sociais: evolução e desafios. Revista Portuguesa de Educação, 16 (2), pp. 221236, 2003.

FELIPE, S. T. Antropocentrismo, Senciocentrismo, Ecocentrismo, Biocentrismo. Agencia de Notícias e Direito Animal, 2009. Disponível em < Disponível em: http://www. anda.jor.br/?p=19279.>, acessado em 26 de Agosto de 2018.

GRUN, M. Em busca da dimensão ética da educação ambiental. São Paulo: Papirus, 2007.

GRUN, M. Ética e educação ambiental: uma conexão necessária. Campinas: Papirus, 1996.

GUIMARÃES, S. S. M. O saber ambiental na formação dos professores de Biologia. 2010. 204f. Tese (Doutorado em Educação Escolar). Universidade Estadual Paulista, Faculdade de Ciências e Letras, Campus de Araraquara, Araraquara - SP. 2010.
KITZMANN, D.; ASMUS, M. Ambientalização sistêmica - do currículo ao socioambiente. Currículo sem Fronteiras, v.12, n.1, pp. 269-290, Jan/Abr 2012.

LEFF, E.; Saber Ambiental. Petrópolis: Vozes, 2001.

MARTINAZZO, C.J. A utopia de Edgar Morin: da complexidade à concidadania planetária. Ijuí: Editora Unijuí, 2002.

MORAES, A. C. R Meio ambiente e Ciências Humanas. $4^{\mathrm{a}}$ ed. São Paulo: Annablume, 2005.

SILVA, L. F. A temática Ambiental, o Processo Educativo e os Temas Controversos: implicações teóricas e práticas para o ensino de Física. 2007. $211 \mathrm{f}$. Tese de doutorado (Doutorado em Educação) -Universidade do Estado de São Paulo, Araraquara, 2007.

TOZONI-REIS, M. F. C. Educação Ambiental e sustentabilidade. Anais... Encontro Internacional de Agroecologia. CD ROM, Faculdade de Ciências Agrárias Agronômicas. Botucatu: 2001.

TRIVELATO, S. L. F. O currículo de ciências e a pesquisa em educação ambiental. Educação: teoria e prática. UNESP, Rio Claro, SP, v. 9, n. 16 e 17, p. 57 - 61, jan./jun. 2001; jul./dez. 2001.

YIN, R. K. Estudo de caso: planejamento e métodos. 4. ed. Porto Alegre: Bookman, 2010.

\section{Sobre os autores}

Victor Hugo de Oliveira Henrique, Graduado em Ciências Biológicas (UFMT), Mestre em Educação (UNESP) e Doutorando em Ciências Ambientais (UNEMAT). Departamento de Biologia - UNEMAT. hugo31_oh@hotmail.com

orcid.org/0000-0002-7019-4088

Luciano Fernandes Silva, Graduação em Licenciatura em Ciências Exatas (USP), Mestre em Educação Escolar (UNESP), Doutorado em Educação Escolar (UNESP). Instituto de Física e Química - UNIFEI orcid.org/0000-0003-20413809 